to Britain to treat the Archbishop of St Andrews for asthma, Grafton misidentifies "Joannes Franciscus" as Sir John Cheke, whose horoscope Cardano had cast, rather than as Jofrancus Offusius, an astrologer temporarily living off Dee's patronage.

For the overwhelming majority of Nature's readers, astrology has been relegated to the rubbish bin of history. Of what use is all this exotic scholarship? Let Grafton speak: "A knowing and thinking subject, Cardano modified, manipulated, or invented contradictory languages as he needed them. He was not always sure why he used them as he did, or on what assumptions they rested, or even whether the predictions he spoke came to him from his own intellect, the stars, or daemonic inspiration. But he knew and said that he stood at the center of a cosmos that his own mind could only mirror in a fractured, incoherent way. He deserves to be heard." Owen Gingerich is at the Harvard-Smithsonian Center for Astrophysics, Cambridge, Massachusetts 02138, USA.

\section{Not just a pretty Polly}

\section{The Alex Studies: Cognitive and Communicative Abilities of Grey Parrots}

by Irene Maxine Pepperberg

Harvard University Press: 2000. 434 pp.

$\$ 39.95, £ 24.95$

\section{John C. Marshall}

From King Solomon to Walt Disney by way of Saint Francis of Assisi, the desire to converse with other species has run deep in the human psyche. The attraction furthermore appears to split we humans into two camps: those who wish to learn the 'language' of animals and those who are determined to teach them ours. On the whole, the former group has scored more scientific victories than the latter. The decipherment of bee dancing, for example, was a far greater achievement than any number of overexcited translations of chimpanzees waving their arms about in a bad imitation of American sign language. Worse, attempts to teach spoken English to apes was even less successful. The entire line of research in which we attempted to impose our communication system on another species was, it seemed, dead. The undertaking had run down the curtain and joined the choir invisible.

Not so. In The Alex Studies, Irene Pepperberg summarizes the first two decades of a project to communicate with African grey parrots (Psittacus erithacus). Pride of place in this enterprise is given to the Alex of the title. In some ways, this research programme has the look of a rational pursuit: parrots,
Pepperberg points out, have "a complex social system and a long life" and, more crucially, they do seem to 'mimic' human speech moderately well. On the debit side, many studies of mimetic birds have conspicuously failed to establish two-way speech communication with humans in properly controlled laboratory settings.

Pepperberg argues convincingly that the kinds of classical and operant conditioning techniques deployed in those prior investigations of mynahs, magpies and parrots were not well matched with the highly interactive, social manner in which mimetic birds acquire calls and songs in their natural environment. Accordingly, she modified an earlier technique of Dietmar Todt's, in which "humans assume roles played by psittacine peers in the wild". In Todt's original procedure, "one human is exclusively the principal trainer of each parrot, asking questions and providing increased visual and vocal attention for appropriate responses. Another human is exclusively the model for the parrot's behavior and simultaneously the parrot's rival for the attention of the principal trainer." In these circumstances, Todt's parrots learned relatively quickly (within a day) to mimic phrases produced by the 'rival'. But this behaviour is more akin to 'antiphonal duetting' than to functional communication, and would not surprise any parrot owner.

In Pepperberg's extension, one human 'trains' another to name objects, and to describe their colour, or shape, or number. The bird watches and is then brought into the game as the second 'pupil'. The two humans sometimes reverse their roles of trainer and trainee, and the bird is occasionally included in three-way interactions. Thus the birds "do not simply hear stepwise vocal duets, but rather observe a communicative process that involves reciprocity". Furthermore, the bird can "effect environment change" (that is, obtain the object) by vocalizing "Wanna ..." plus some word in its vocabulary. The evidence presented suggests that Alex could acquire vocal labels for objects, actions and attributes to a level similar to that reached in earlier experiments with great apes taught to deploy visual signs or tokens.

Some generalization to novel situations is found, along with a very limited combinatorial ability. There were also indications that Alex can respond appropriately to sameness, difference and absence. Comprehension of relative size was fair, and that of object permanence was good, comparable to that demonstrated in young children by the Swiss developmentalist Jean Piaget.

For my money, the most interesting chapters were those concerned with just how similar (or dissimilar) to human speech is the parrot's imitation, and how the bird actually produces these sounds with a vocal apparatus that is very different from our own. In a sense, these chapters tell us as much about humans as about parrots - however distorted the signal, we are predisposed to hear speech. The final chapter includes fascinating information about the social behaviour of mimetic birds in the wild, and makes one wish for an entire book on this topic.

With respect to captive parrots, readers will have to make up their own minds about whether it was all worth the effort (on either Alex's part or that of Pepperberg). I suspect that those who were unimpressed by the proto-linguistic skills of chimpanzees and dolphins will remain undazzled by those of parrots. But people who thought these earlier attempts at interspecies communication were a major breakthrough in evolutionary science will no doubt be delighted with Alex's achievements and untroubled by how far back one must go to find a common ancestor

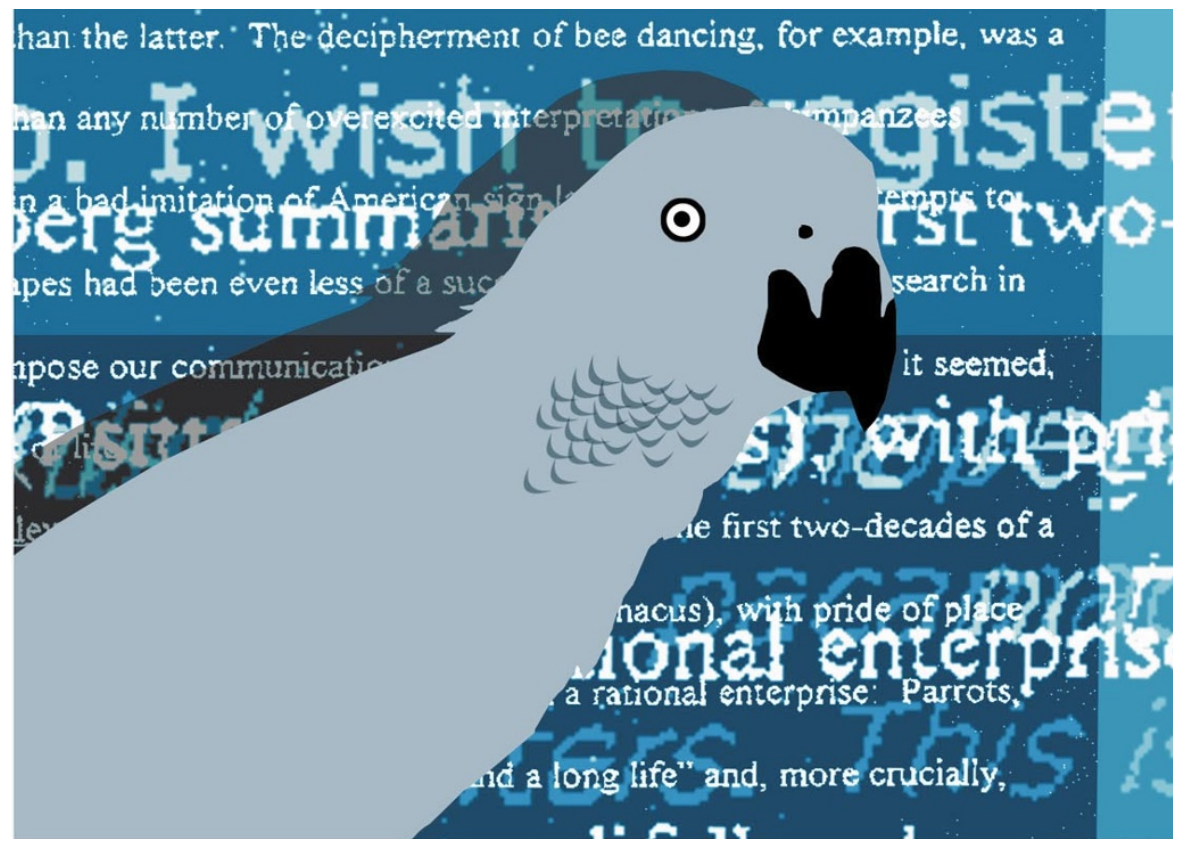


of parrots and humans. On the credit side, Pepperberg gives an excellent justification for her training procedures, the descriptions of the results are detailed and lucid, and, best of all, the interpretations are calm and considered. Pepperberg is well aware of Occam's razor and is careful not to indulge in ridiculous overinterpretations. One might nonetheless wonder what exactly was the point of this labour of love. To misquote Ludwig Wittgenstein, what would a parrot tell us if it could talk? Not a lot, seems to be the answer. Is a research programme to teach human speech to parrots likely to lead to deeper insights than one devoted to teaching us the calls and songs of the parrot?

Pepperberg's justification is that her data might help to improve the lives of captive parrots, "prevent habitat destruction and capture of birds in the wild, or enable researchers to develop better animal models for various human dysfunctions". I hope she's right.

John C. Marshall is in the Neuropsychology Unit, University Department of Clinical Neurology, Radcliffe Infirmary, Woodstock Road, Oxford OX2 6HE, UK.

\section{Communications from the dead}

\section{Dear Mr Darwin: Letters on the Evolution of Life and Human Nature \\ by Gabriel Dover \\ Weidenfeld \& Nicolson: 2000. 268 pp. $£ 20$}

\section{A. J. Berry}

In 1876 Charles Darwin contributed $£ 10$ - a substantial amount at that time - to the costs of the criminal prosecution of Henry Slade, a renowned spiritualist medium. Slade, his accusers charged, was a fraud, and his séances were merely elaborate exercises in legerdemain. Remarkably, the case pitted the two discoverers of natural selection against each other: Alfred Russel Wallace, author of an approving book on spiritualism, was the defence's star witness. Despite Wallace's characterization of the defendant as an "earnest inquirer after truth in the department of Natural Science", Slade was convicted. Darwin was delighted; he had no time for the "clever rogues" who preyed upon grieving relatives anxious to contact a loved one.

Darwin, who died in 1882, may now have cause to reconsider his attitude towards posthumous communication as he himself has recently taken to holding forth from beneath the flagstones of Westminster Abbey. The medium in this case is geneticist Gabriel Dover, whose book, Dear Mr Darwin, comprises a series of letters between Dover and Darwin. Dover brings Darwin up to date on

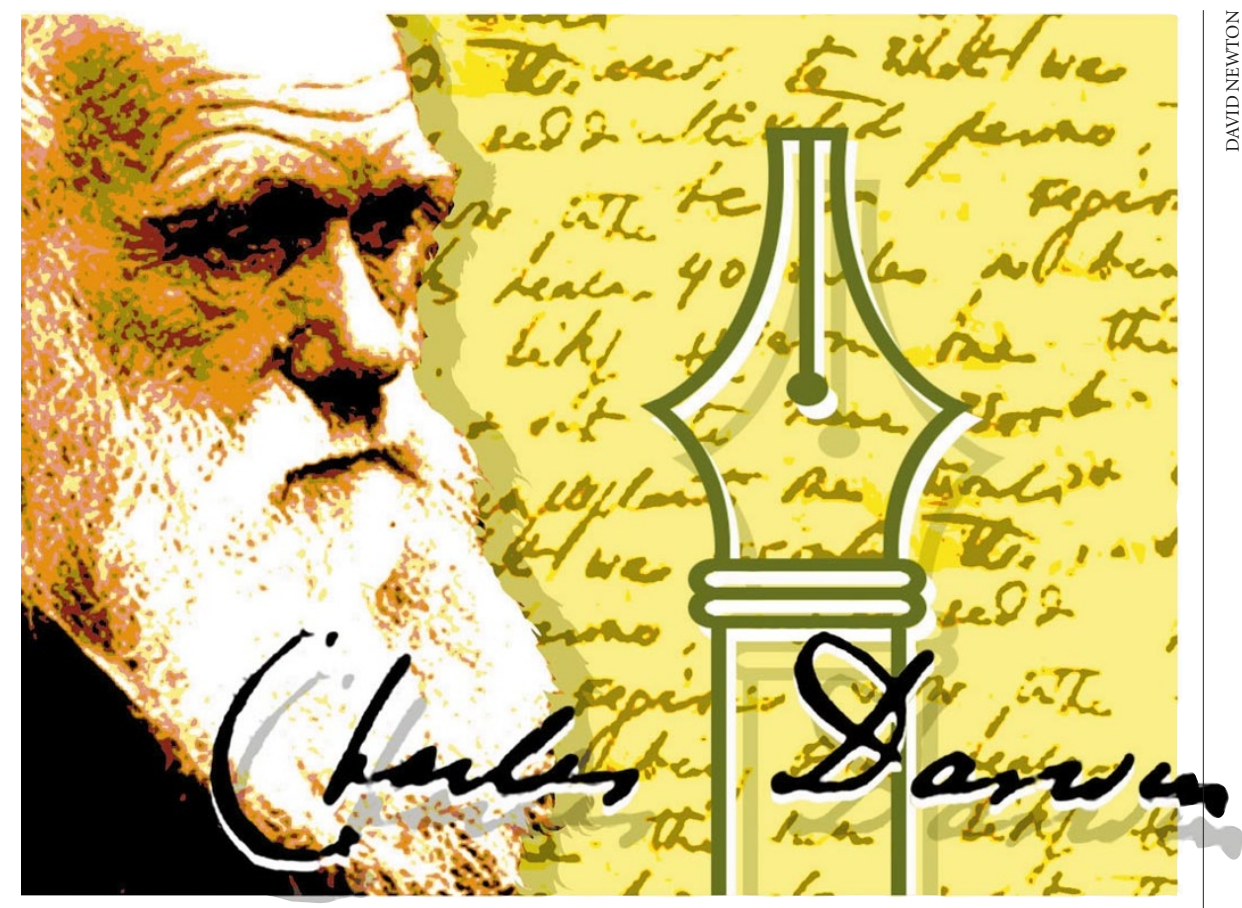

evolutionary biology since 1882, and Darwin, for his part, supplies appreciative yet inquisitive responses.

Things start rather formally — it's "My Dear Dover ... Ever your most truly, Charles Darwin" to begin with — but become increasingly chummy as the correspondence develops - it's "Dear Gabby.... Your most sincere friend, Chas. Darwin" by the end. The gimmick is almost painfully cute, but Dover handles it deftly: he is not unduly deferential, and his Darwin not overly impressed by what Dover has to say. The result is a quirky but readable account of the Dover perspective on modern evolutionary biology.

Darwin's education, however, is in idiosyncratic hands. At the outset, Darwin must predictably swallow doses of Mendel and Hardy-Weinberg, but the textbooks are then quickly forsaken when, on the second page of Dover's second letter, we run into his pet theory, 'molecular drive'. This, Darwin learns, is, along with natural selection and genetic drift, one of "the three forces of evolution". Much of the book is dedicated to explicating molecular drive and to justifying its exalted place in Dover's pantheon of evolutionary forces.

Dover introduced the term in the early 1980s after DNA-sequencing studies of multi-gene families - groups of related genes that often sit side by side along chromosomes - had revealed a striking and unexpected evolutionary pattern now known as 'concerted evolution'. Within a species, all members of a gene family may be identical, or at least very similar, whereas between even closely related species we see plenty of sequence divergence between homologous gene families. The homogenization of genefamily members within species is caused by a number of simple and well-understood genetic processes, primarily unequal crossing over and gene conversion. Molecular drive is, in Dover's words, an "umbrella term" covering these and other "non-Mendelian mecha-

Does molecular drive really rank beside selection and drift as one of the primary determinants of evolutionary change? Hardly. Darwin distinguished between two fundamental aspects of the evolutionary process: the genesis of variation, and the subsequent fate of that variation. In creating new configurations of existing genetic variation, molecular drive definitely contributes to step one. But does it contribute to step two? In principle, a variant can indeed spread through a gene family by molecular drive, especially when there are asymmetries in the drive process. For example, gene conversion is sometimes 'biased' such that an $a$ allele is more likely to be converted to an $A$ than an $A$ to an $a$; such a situation may result in a molecularly driven increase of the $A$ allele.

But crucially, the ultimate fate of any variant, whether subject to molecular drive or not, is determined by its impact on fitness: natural selection will intervene if it either enhances or diminishes its bearer's chance of reproduction. If the variant has no such impact - it is selectively neutral - then genetic drift is usually the major player, also play a role. Molecular drive's contribution to the second phase of the evolutionary process is thus subordinate to the 'traditional' forces determining the fate of genetic variation in natural populations. Molecular drive is an interesting evolutionary phenomenon, but it is false advertising to bill it as a third major force of evolution.

Dover's Darwin, whose critical facilities nisms of inheritance". although molecular drive may sometimes 